\title{
Patho-biochemical biomarkers of hepatotoxicity on exposure to bifenthrin insecticide in birds (Columba livia)
}

Shakeel Ahmed Memon ${ }^{1 *}$, Nasreen Memon ${ }^{2}$, Shamsuddin Ahmed Shaikh ${ }^{1}$, Zubeda Butt ${ }^{1}$ and Bhojoo Mal ${ }^{1}$

1. Department of Zoology, University of Sindh, Jamshoro-76080, Pakistan

2. Meritorious Professor and Chairperson, Department of Zoology, University of Sindh, Jamshoro-76080, Pakistan

*Corresponding author's email: shakeel_memon70@yahoo.com Cell \# 0300-3069383

\section{Citation}

Shakeel Ahmed Memon, Nasreen Memon, Shamsuddin Ahmed Shaikh, Zubeda Butt and Bhojoo Mal. Pathobiochemical biomarkers of hepatotoxicity on exposure to bifenthrin insecticide in birds (Columba livia). Pure and Applied Biology. Vol. 4, Issue 4, 2015, pp 597-604. http://dx.doi.org/10.19045/bspab.2015.44019

Received: $14 / 08 / 2015$

Revised: 05/11/2015

Accepted: $14 / 11 / 2015$

Abstract

Ecotoxicological impacts of pyrethroid insecticides are getting attention to their indiscriminate use in agriculture sector. The aim of present experimental study was to evaluate the possible hepatotoxic effects bifenthrin insecticide in avian species. For this purpose, 36 Pigeons were (Columba livia domestica) randomly divided in three equal group (A, B \& C). Oral doses $1 / 20^{\text {th }}$ \& $1 / 15^{\text {th }}$ of $\mathrm{LD}_{50}(22 \mathrm{mg}$. and $30 \mathrm{mg} . / \mathrm{kg}$./day) of bifenthrin were administrated to test group A and $\mathrm{B}$ respectively for 40 consecutive days, whereas group $\mathrm{C}$ birds kept as control. All birds were supplied same quantity of food and water. A highly significant decrease $(\mathrm{P}<0.001)$ in the body weight was recorded in both test group birds as compared to group C. Treated birds demonstrated change in color of the liver with paleness to yellowish coloration. Microscopic examinations revealed that, transverse section liver was showing enlarged hepatocytes increased sinusoidal spaces, vacuolation of hepatocytes and inflammatory cells with hypertrophy at the oral dose of (22 mg./kg./day). While oral dose of bifenthrin $(30 \mathrm{mg} . / \mathrm{kg} . /$ day) exerted marked histopathological changes in the liver of group B birds like diffused vacuolation, congestion and deterioration of the hepatocytes, haemorrhages and hepatic fibrosis. The findings of present study revealed that bifenthrin insecticide exerted toxic effects in exposed pigeons and can produce moderate to severe hepatic alterations in the avian species in proportion to exposure level and duration.

Keywords: Pigeons; Bifenthrin; Toxic effects; Hepatic tissues

\section{Introduction}

Many avian species have shown enormous declines and this mainly associated with indiscriminate use of agrochemicals. In agriculture sector various insecticides are frequently used to kill the noxious pests for increase in crop yields, consequently cause severe health and ecotoxicological problems in non-target living organisms like birds and other wildlife. Birds play a vital ecological role as well as it is one of the most important sources of food. Pyrethroids insecticides are commonly used in agriculture and house hold applications to control and eradicate 
ectoparasites and insects. Avian species always remain under stress in presence of these contaminants. This stress is consequently leading to decline avian population. Due to their economical and commercial importance, these animals must be protected from these threats. It has been reported that the agrochemicals alone affect $87 \%$ of the globally threatened bird species [1]. Various bird species could have higher threat from the prevailing risks of insecticides in agro-ecosystem [2, 3]. Average body weight of the jungle babbler decreased during the cotton spray season as compared to the non-cotton season in the same area [4]. Exposure to pesticides results histopathological changes in the liver of birds [5]. Birds exposed to insecticides show alteration in the tissues of liver like peripheral fibrosis with mononuclear cells, increase in bile duct and vacuolation of hepatocytes [6]. Synthetic pyrethroids are frequently used in agriculture sector to control harmful pests [7]. Bifenthrin is a neurotoxicant synthetic pyrethroid insecticide and commonly used for agricultural applications [8]. Recently risk assessment for bifenthrin has been developed for short- term and long-term exposures [9]. Birds are susceptible to bifenthrin toxicity during spraying in the agricultural fields. Exposure to the referred agrochemical causes severe health problems to varieties of avian species culminating great ecological risks and economical loss [10]. Moreover this also causes a potential hazard to human health due to the presence of pesticides residues in meat. Liver is one of the most important gland and play a vital role in digestion, metabolism, synthesis, storage and detoxification. The liver is a possible target organ of pesticide toxicity and exposure to these insecticides may cause histopathological alterations or direct damage to liver. The present study was carried out to evaluate the numerous toxic effects of bifenthrin insecticide on hepatic tissues. Therefore findings of the present investigation are in the context of valuable bioindicator for adverse effects on human health and other eco-toxicological hazards.

\section{Materials and Methods}

\section{Experimental Animals}

To determine the toxicity, 36 healthy Pigeons (Columba livia domistica) were used and purchased from local hatcheries of different villages. These birds reread in clean wooden cages with metal nets $\left(12^{\prime} \mathrm{x}\right.$ 16') sq. ft. in laboratory, Department of Zoology, University of Sindh, Jamshoro. Thereafter all birds were acclimatized for 30 days before starting of the experimental studies. All birds were maintained on grains, seeds and clean tap water.

\section{Experimental Design}

After acclimatization all pigeons were randomly divided in to three equal groups ( $\mathrm{A}, \mathrm{B} \& \mathrm{C}$ ) having 12 pigeons each and their weight was recorded before start of the experiment. The treatment was carried out for 40 days in test group A and B respectively, whereas group $\mathrm{C}$ kept as control. All birds were supplied same quantity of food and water.

\section{Test Chemical Preparations and Experimental Protocol}

During experimental period synthetic pyrethroid insecticide (Bifenthrin EC 10) was applied in Pigeons (Columba livia). The insecticide solution was applied on LD50 concentration of technical products determined according to the toxicology method [11]. Oral doses $1 / 20^{\text {th }} \& 1 / 15^{\text {th }}$ of $\mathrm{LD}_{50} \quad$ (22mg. and $\left.30 \mathrm{mg} . / \mathrm{kg} . / \mathrm{day}\right)$ of bifenthrin were administrated to each test group bird for 40 consecutive days by adding in $5 \mathrm{ml}$ distilled water while the control group received tap water for the same time period. During experimental period test group birds were monitored for clinical and physical symptoms. At the termination of experiment body weight of all birds was recorded. Thereafter blood samples were drawn from each group of 
birds and centrifuged on $5000 \mathrm{rpm}$ for liver biochemical estimation of aspartate aminotransferase (AST), alanine aminotransferase (ALT), and alkaline phosphatase (ALP). On the last birds were randomly dissected out to retain the liver for histological observations.

\section{Organ Morphology and Histological Procedure}

After dissection removed organs were examined for gross changes and parts of retained organs were fixed in Bouin's fluid for 24 hours. Tissues dehydration procedure was performed by alcohol series and finally embedded in paraffin wax. For histopathological observation $6 \mu \mathrm{m}$ thick sections cut on Rotary microtome machine and stained through Harris's hematoxylin (Gurr, 1956) and Eosin (Putt, 1948) series. The histological examinations and microphotography were performed on Leica DM-2500 biosystem.

\section{Statistical Analysis}

Statistical analysis was performed through One-way ANOVA.P values $(<0.05)$ and $(<$ $0.01)$ considered as statistical significant and values described as Mean \pm SD. LSD test was carried out to compare difference between each group means by using (Statistics 8.1) program.

\section{Results and Discussion}

Effects on Food intake, Health and

Mortality
Pyrethroid insecticides are widely used in agricultural fields for noxious pest control and parasitic management in livestock sector. The Bifenthrin insecticide is commonly applied in agriculture sector and exhibits severe toxic effects in exposed organisms [12, 13]. Animals exposed to bifenthrin insecticides produces significant decline in their body weight [14]. During present experimentation after oral administration of bifenthrin at dose of (22mg. and 30mg./kg./day) for 40 consecutive days, it was observed that all treated birds of group A and B stopped food intake temporarily whereas as group $\mathrm{C}$ pigeons were comparatively normal in food intake. A highly significant decrease $(\mathrm{P}<$ 0.001 ) in the body weight was recorded in both test group birds as compared to control group $\mathrm{C}$ (Table 1). This showed drastic toxic effects on over all body mass. During present experimental study clinical symptoms like tremors, nausea, dizziness, fatigue and trembling were observed in treated birds and clinical symptoms on exposure to bifenthrin in trout fishes and pyrethroid toxicity in animals reported by different researchers [15-17]. Three birds died due to the toxic effects of bifenthrin one in group A on day 15 and two in group $\mathrm{B}$ on day 10 and 15 , while no mortality was observed in group $\mathrm{C}$.

Table 1. Indicates (Mean) bodyweight in Test group Pigeons with highly significant decrease $(P<0.001){ }^{* *}$ as compared to control group. Values not sharing same letters are showing significantly different

\begin{tabular}{|c|c|c|c|c|}
\hline No. & Birds (Pigeons) & & $\begin{array}{c}\text { No. Of Birds } \\
(\mathbf{n = 3 6})\end{array}$ & $\begin{array}{c}\text { Body Weight } \\
(\text { Mean } \pm \text { S.D) grams }\end{array}$ \\
\hline 1 & Test group A & $58 \mathrm{mg}$. & 11 & $229.9 \pm 6.96 \mathrm{~b}^{* *}$ \\
\hline 2 & Test group B & $80 \mathrm{mg}$. & 10 & $221.25 \pm 4.67 \mathrm{c}^{* *}$ \\
\hline 3 & Control group C & (NO Dose) & 12 & $257.66 \pm 8.36 \mathrm{a}$ \\
\hline
\end{tabular}




\section{Liver Morphology and Histopathology Morphology}

The indiscriminate use of pesticides is very common in agro fields with no procedural guidelines and protective measures even used pesticide containers are disposed in the surroundings. Toxic effects of these agrochemicals on non-target organisms including birds and fishes are documented [18-20]. It is also documented that different synthetic pyrethroid insecticides induce numerous histological alterations in metabolic organs [21]. In present study, treated birds change in color of the liver was observed with paleness to yellowish coloration as compared to the liver of the control group pigeons which was dark brown colored and normal in size. It consists of two inter connected asymmetrical lobes. However significant increase in weight of the liver in test group $\mathrm{A}$ and $\mathrm{B}$ was recorded in comparison with the birds of group $\mathrm{C}$ (Fig.1).

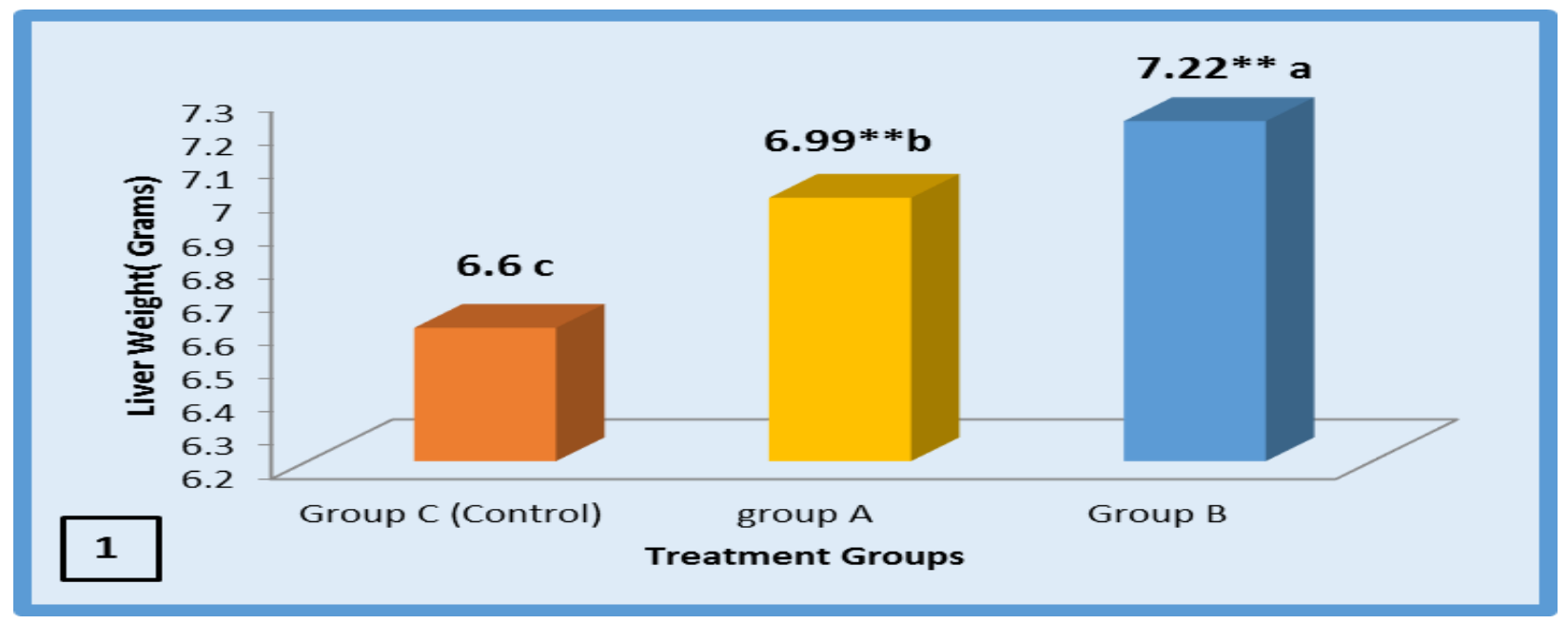

Fig. 1. Showing liver weight in treated group A \& B pigeons with highly significant increase $(\mathbf{P}<0.01) * *$ as compared group c (control group). Values not sharing same letters are significantly different with each other

\section{Histopathology}

Histopathological alterations have been documented as systemic toxicity in birds and mammals [22]. Exposure to bifenthrin insecticide produce enlarged hepatocytes, increased sinusoidal spaces, vacuolation of hepatocytes, pycnotic nuclei and inflammatory cells with hypertrophy in most of the treated fishes [23]. In present study same microscopic changes were observed in the liver of group A birds on the oral dose of bifenthrin (22mg./kg./day) for consecutive 40 days (Fig. 2-3). The liver is the vital metabolic organ for the detoxification and hepatic toxicity of pyrethroid agrochemicals is associated with necrosis [24]. While at the oral dose of bifenthrin $(30 \mathrm{mg} . / \mathrm{kg} . / \mathrm{day})$ for same duration exerted marked histopathological changes in the liver of group B birds. The severity of the lesions in the liver showed hypertrophy, deterioration of the hepatocytes, haemorrhages, hepatic fibrosis and necrosis of hepatocytes (Fig. 45). There were no significant changes were seen in the sections of liver of the group $C$. Normal hepatocytes with numerous sinusoid space and walls of sinuses having Kupfer cells (Fig. 6-7). Bifenthrin exposure in goat 
cause significant variations in the hepatic enzymes of living organism which ultimately increase serum aspartate aminotransferase (AST) and serum alanine aminotranferase (ALT) and alkaline phosphatase (ALP) [25]. Similarly, bifenthrin treated rats demonstrated significant increase in hepatic enzymes (AST, ALT and ALP) [26]. In present investigations oral administration of bifenthrin produced significant increase in serum level of liver enzymes AST, ALT and ALP in Group A and B birds as compared to group $\mathrm{C}$ birds (Table 2). These pathophysiological and biochemical alterations are biomarkers of liver toxicity. It is concluded that adverse effects of bifenthrin insecticide induced severe hepatic injuries, impairment and dysfunction of metabolic, immune and detoxification mechanism in birds.

Tab.2. Data for biochemical parameters showing highly significant increase $(\mathbf{P}<0.001) * * *$ and $(\mathbf{P}<0.01)^{* *}$. Values sharing not same letters are significantly different with each other on $(P<0.05)$. Serum Alanine Aminotranferase (ALT), Aspartate Aminotransferase (AST) and Alkaline Phosphatase (ALP)

\begin{tabular}{|c|c|c|c|}
\hline $\begin{array}{c}\text { Pigeons } \\
\text { (Groups) }\end{array}$ & $\begin{array}{c}\text { (ALT) } \\
\text { Mean } \pm \text { SD } \\
\text { U/L }\end{array}$ & $\begin{array}{c}\text { (AST) } \\
\text { Mean } \pm \text { SD } \\
\text { U/L }\end{array}$ & $\begin{array}{c}\text { (ALP) } \\
\text { Mean } \pm \text { SD } \\
\text { U/L }\end{array}$ \\
\hline $\begin{array}{c}\text { Control } \\
\text { (Group C) }\end{array}$ & $16.9 \pm 2.57^{\mathbf{C}}$ & $118 \pm 14.99 \mathbf{C}$ & $300 \pm 36.76^{\mathbf{C}}$ \\
\hline $\begin{array}{c}\text { Treated } \\
\text { (Group A) }\end{array}$ & $32.7 \pm 5.60^{* * \mathbf{b}}$ & $647 \pm 48.70^{* * * \mathbf{b}}$ & $717 \pm 88.50^{* * \mathbf{b}}$ \\
\hline $\begin{array}{c}\text { Treated } \\
\text { (Group B) }\end{array}$ & $40.3 \pm 4.93 * * \mathbf{a}$ & $717 \pm 24.60^{* * * a}$ & $835 \pm 93.33^{* * \mathbf{a}}$ \\
\hline
\end{tabular}
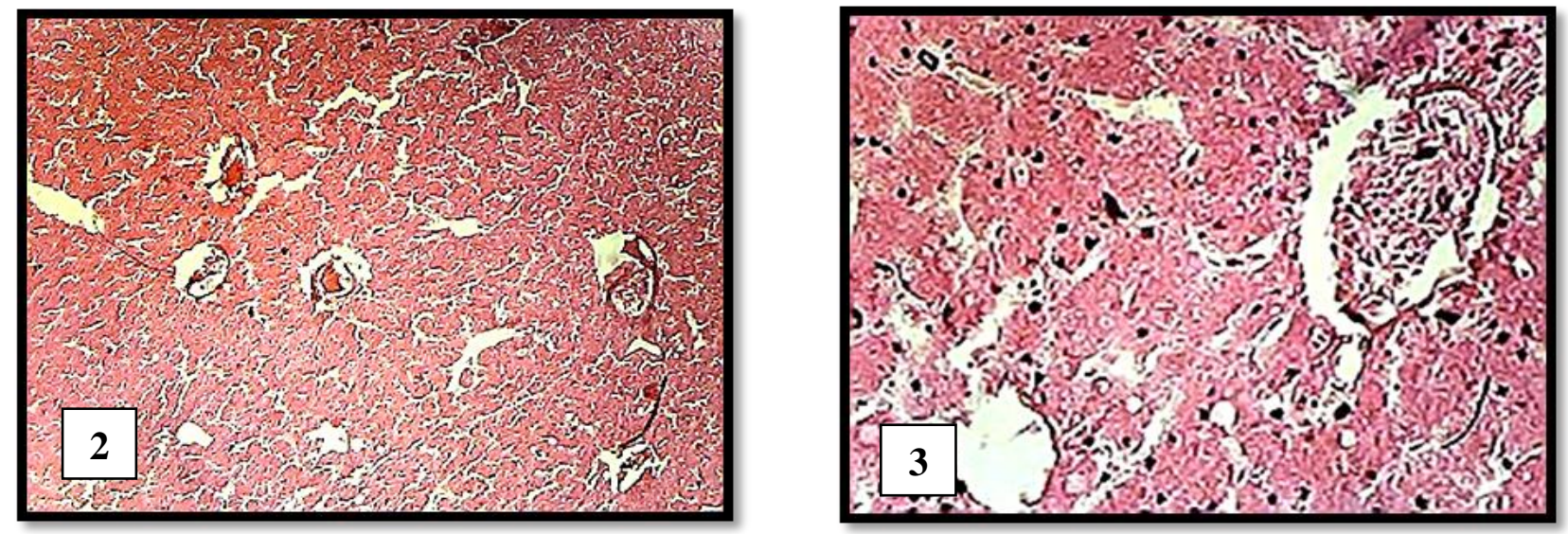

Figs. 2-3. Histopathological section of liver showing enlarged hepatocytes with inflammation, vacuolation and congested ducts in treated pigeons Group $\mathrm{A},(\mathrm{H} \& \mathrm{E}, \mathrm{x10} \&$ x40) 

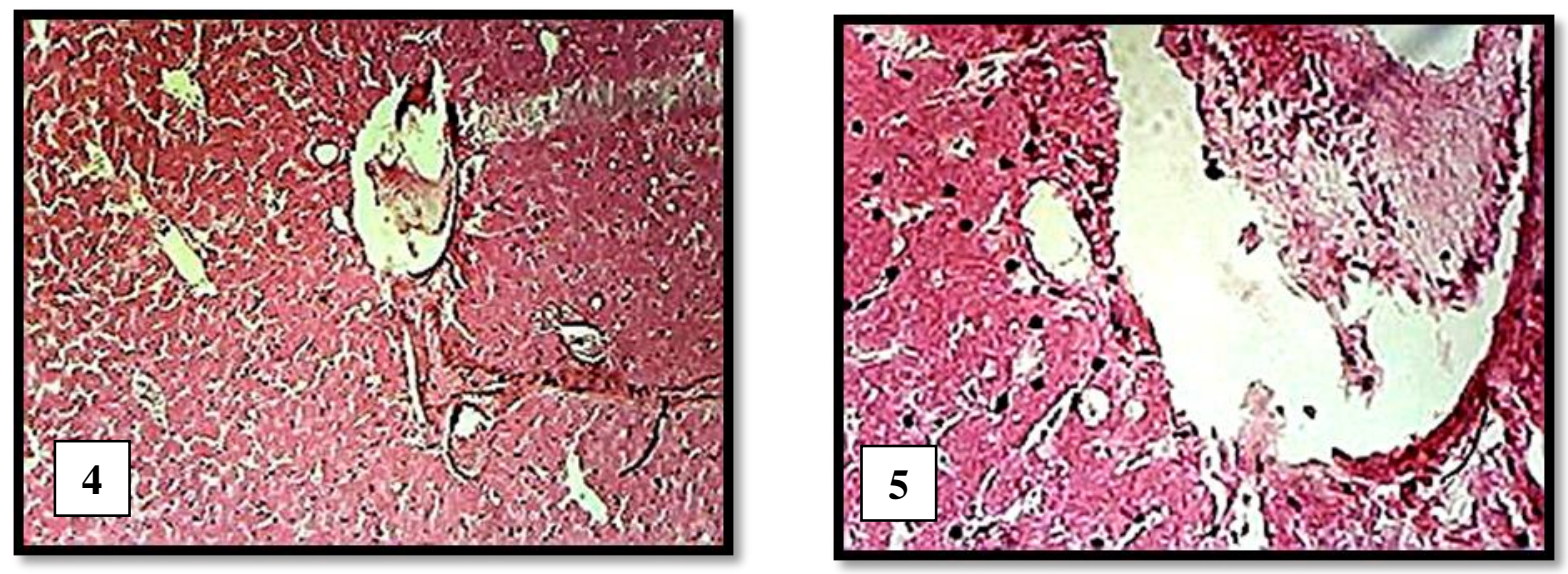

Figs. 4-5. Section of liver showing hypertrophy, deterioration of the hepatocytes and increase diameter of bile duct in test group B, (H \& E, x10 \& x40)
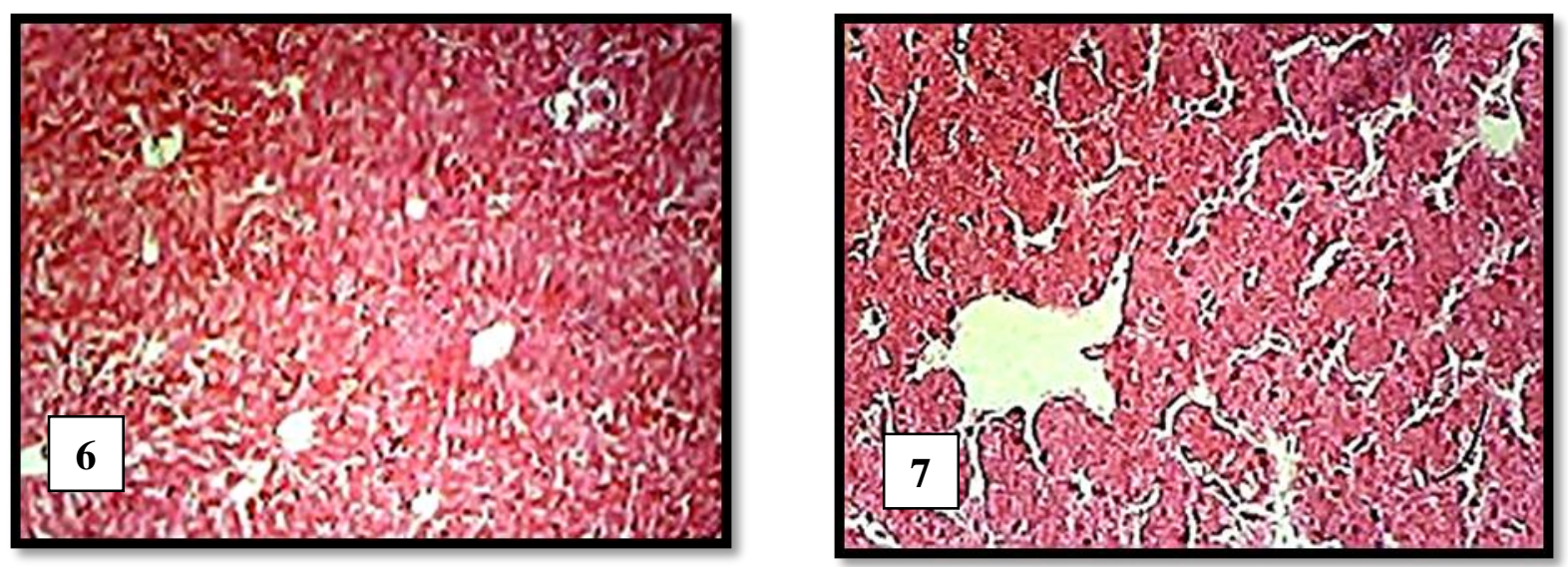

Figs.6-7. Liver section of the control group pigeons showing normal histological structure of hepatic cells with proper sinusoid space having Kupfer cells. This also showing normal diameter of bile ducts $(H \& E, x 10 \&$ x40)

Authors' contributions

Conceived and designed the experiments: SA Memon, N Memon \& SA Shaikh. Performed the experiments: SA Memon. Analyzed the data: SA Memon, N Memon \& SA Shaikh. Contributed reagents/materials/analysis tools: $\mathrm{SA}$ Memon, Z Butt \& B Mal. Wrote the paper: SA Memon \& N Memon

\section{References}

1. Atef MAA (2010). Physiological and histopathological investigations on the effects of $\alpha$-lipoic acid in rats exposed tomalathion. Journal of Biomedicine and Biotechnology 8: 232-240.

2. Bahaa AAS (2012). Effects of Sub Chronic Exposure of Diazinon on Wild Pigeon (Culumba livia gaddi) at Basrah City/Southern Iraq. International 
Journal of Poultry Science 11 (2): 147152.

3. BLI (2008). State of the world's Birds: Indicate for Changing World. Bird Life International Cambridge, UK.

4. Hasnain T (1999). Pesticide-use and its impact on crop ecologies: issues and options. Working Paper Series No. 42 Sustainable Development Policy Institute (SDPI), Islamabad, Pakistan.

5. Hussain I and Afzal M (2005). Insectivorous birds and their significance in a cotton wheat based agroecosystem of Punjab, Pakistan. Pakistan J. Zool., 37: 133-143.

6. Jabbar A, Masud ZA, Parveen Z and Ali M (1993). Pesticide residues in cropland soils and shallow groundwater in Punjab, Pakistan. Bull. Environ. Contam. Toxicol. 51: 268-273.

7. Aslam F, Khan A, Khan MZ, SharafS, Gul ST and Saleemi MK (2010). Toxico-pathological changes induced by cypermethrin inbroiler chicks: Their attenuation with vitamin $\mathrm{E}$ and selenium. Exp.Toxicol. Pathol., 62: 441-450

8. Ahmad L, Khan A and Khan MZ (2011). Cypermethrin induced biochemical and hepato-renal pathological changes in rabbits. Int. J. Agric. Biol., 13: 865-872

9. US EPA 2011. Pyrethroid cumulatice risk assessment

10. Velisek J, Wlasow T, Gomulka P, Svobodova Z, Dobsikova R, Novotny L, Dudzik M. (2006): Effects of cypermethrin on rainbow trout (Oncorhynchus mykiss). Veterinarni Medicina, 51: 469-476.

11. Weil CS (1952) Tables for convenient calculation of median effective dose (LD 50 or ED 50) and instructions in their use. Biometrics. 8:249.

12. Falicia LE, Clement GY and Tchounwou PB (2011). Involvement of oxidative stress in methyl parathion and parathion-induced toxicity and genotoxicity to human liver carcinoma (Hepg2) cells. Environ. Toxicol., DOI 10.1002/tox.20725.

13. Suresh BN, Aggarwal M, Ranganathan V, Sarkar SN, Kataria M and Malik J (2009). Effects of simultaneous repeated exposure at high levels of arsenic and malathion on hepatic drugbiotransforming enzymes in broiler chickens. Environ. Toxicol. Pharmacol., 28: 213-218.

14. Akhtar N, Kyani SA, Ahmad MM \& Shahab M (1996). Insecticide-induced changes in secretory activity of the thyroid gland in rats. J.Appl. Toxicol., 16(5): 397- 400.

15. Prashanth MS, David M, Mathed SG (2005): Behavioural changes in freshwater fish, Cirrhinus mrigala (Hamilton) exposed to cypermethrin. Journal of Environmental Biology, 26: 141-144.

16. Dobsikova R, Velisek J, Wlasow $\mathrm{T}$, Gomulka P, Svobodova Z, Novotny L (2006). Effects of cypermethrin on some haematological, biochemical and histopathological

parameters of common carp (Cyprinus carpio L.). Neuroendocrinology Letters, 27:101-5

17. Bradbury SP and Coats JR (1989). Comparative toxicology of the pyrethroid insecticides. Reviews of Environmental Contamination and Toxicology, 108: 133-177.

18. Uzun FG, Kalender S, Durak D, Demir F, and Kalender Y (2009). Malathioninduced testicular toxicity in male rats and the protective effect of vitamins $\mathrm{C}$ and E, Food. Chem. Toxicol., 47:19031908.

19. Sodhi SA, Sharma APS, Brar and Brar RS (2008). Effect of a tocopherol and selenium onantioxidant status, lipid- 
peroxidation and hepatopathy induced by malathion in chicks. Pest. Biochem. Phys., 90: 82-86.

20. Moore P, Yedjou CG and Tchounwou PB (2009). Malathion-induced oxidative stress, cytotoxicity and genotoxicity in human liver carcinoma (HepG2) cells. Environ. Toxicol. 25: 221-226.

21. Uzunhisarcikli M, Kalender Y, Dirican $\mathrm{K}$, Kalender S, Ogutcu A and Buyukkomurcu F (2007). Acute, subacute and subchronic administration of methyl parathion-induced testicular damage in male rats and protective role of vitamins $\mathrm{C}$ and E. Pestic. Biochem. Phys., 87: 115-122.

22. Mossalam HH, Abd-El AOA, Morgan EN, Youssaf SMS and Mackawy AMH (2011). Biochemical and ultra-structure studies of the antioxidant effect of aqueous extract of Hibiscussabdariffa on the nephrotoxicity induced by organophosphorous pesticide (malathion) on the adult albino rats. Life. Sci. J., 8: 561-574.

23. Velisek G, Svobodova Z, Machova J (2009). Effects of bifenthrin on some haematological, biochemical and histopathological parameters of common carp (Cyprinus carpio L.). Fish Physiology and Biochemistry 35: 583-590.

24. Sayeed I, Parvez S, Pandey S, BinHafeez B, Haque R, Raisuddin S, (2003). Oxidative stress biomarkers of exposure to deltamethrin in freshwater fish, Channa punctatus Bloch Ecotoxicol Environ. Saf., 56: 295-301.

25. Khan AM, Sultana M, Raina R, Verma PK and Dubey N (2013) Effect of SubAcute Oral Exposure of Bifenthrin on Biochemical Parameters in Crossbred Goats Proceedings of the National Academy of Sciences, India Section B: Biological Sciences 83(3): 323-328.

26. Khan A, Faridi HA, Ali M, Khan M. Siddique M, Hussain I (2009) Effects of cypermethrin on some clinico-hematobiochemical and pathological parameters in male dwarf goats (Capra hircus). Exp.Toxicol. Patho., 61(2): 151-160. 